\title{
LA BREVE DIFESA DEI DIRITTI DELLE DONNE: POR UNA REIVINDICACIÓN EFECTIVA E IGUALITARIA DE LOS DERECHOS DE LAS CIUDADANAS
}

\section{THE BREVE DIFESA DEI DIRITTI DELLE DONNE: FOR AN EFFECTIVE AND EQUAL CLAIM OF THE RIGHTS OF FEMALE CITIZENS}

\author{
Mercedes González de Sande \\ Universidad de Oviedo, Oviedo, España \\ gonzalezmercedes@uniovi.es \\ https://orcid.org/0000-0002-2404-9306
}

Recibido: octubre de 2021

Aceptado: noviembre de 2021

Palabras clave: Ilustración, querella de las mujeres, derechos, igualdad, siglo XVIII, Rosa Califronia.

Key words: Enlightenment, the woman question, rights, equality, eighteenth century, Rosa Califronia.

Resumen: El siglo XVIII será un período crucial en la lucha de las mujeres por la reivindicación de sus derechos. El espíritu revolucionario de la Ilustración había penetrado también en ellas, que anhelaban ansiosas la llegada de un giro definitivo que culminase en una transformación radical de la sociedad, donde, finalmente, hubiera cabida para ambos sexos en igualdad de condiciones. Sin embargo, la tan aclamada proclamación de la Declaración de los derechos del hombre y del ciudadano, aprobada en París, en 1789, ante todo pronóstico, las excluirá de la esfera de los derechos humanos. Muchas fueron las reacciones en toda Europa contra tamaña injusticia, entre ellas la publicación, en Italia, en 1794, del tratado Breve difesa dei diritti delle Donne, del que daremos cuenta en el presente artículo.

Abstract: The 18th century will be a crucial period in the women's fight for the vindication of their rights. The revolutionary spirit of the Enlightenment had also penetrated them, who anxiously longed for the arrival of a definitive turn that would culminate in a radical transformation of society, where, finally, there would be room for both sexes on equal terms. However, the acclaimed proclamation of the Declaration of the Rights of Man and of the Citizen, approved in Paris in 1789, above all expectations, will exclude them from the sphere of human rights. There were many reactions in Europe against such injustice, among them the publication, in Italy, in 1794, of the treatise Breve difesa dei diritti delle Donne, which we will give an account of in this article. 


\section{l. Las mujeres de la llustración y la lucha en defensa de sus derechos}

A partir del Renacimiento y, en particular, desde los comienzos del siglo XVIII, la malograda condición de las mujeres había experimentado progresivas mejoras. Especialmente, las pertenecientes a las clases más acomodadas, habían ido adquiriendo mayor libertad con respecto a las épocas pasadas; no obstante aún no gozasen de las mismas oportunidades que los hombres, al no ser consideradas ciudadanas a pleno derecho y depender legalmente de la autoridad masculina ${ }^{1}$. Por otra parte, en las familias aristocráticas y de la alta burguesía, se había difundido cada vez más la importancia y utilidad de garantizar cierta instrucción a las jóvenes ${ }^{2}$, aunque esta fuera inferior a la de los varones.

Proporcionar determinada formación a las mujeres, por limitada que esta fuera, comenzaba a considerarse cada vez más útil, puesto que, de este modo, podrían cumplir mejor con sus obligaciones, tanto con su familia, educando a sus hijos y agradando a sus esposos, como fuera de esta, dando una buena imagen en sociedad y manteniendo conversaciones adecuadas y dignas de su linaje.

Los prejuicios contra la educación femenina iban desapareciendo, de forma par-

1. Sobre la evolución de las mujeres desde el Renacimiento hasta el siglo XVIII, recomiendo Matthews-Grieco, S. F. (2001).

2. En la formación de las mujeres, en la mayoría de los casos, aún quedaba excluida la educación literaria por la arraigada idea de que esta pudiera malearlas y distraerlas de sus verdaderas labores, que continuaban siendo, esencialmente, las domésticas. ticular, entre las familias más pudientes, que permitían y proporcionaban a sus hijas una cultura más amplia, apoyándolas en su formación. Asimismo, algunos varones también contribuyeron a la instrucción de sus esposas, ofreciéndoles sus conocimientos y la posibilidad de formarse con ellos; como es el caso, entre otras muchas, de la química Marie Anne Pierrette Paulze (1758-1836), esposa del científico Antoine Laurent de Lavoisier, gracias a cuyas enseñanzas y permisividad a la hora de desarrollar su talento llegó a ser considerada "la madre de la química moderna".

Precisamente, debido a este terreno favorable para la instrucción femenina, en este período, fueron cada vez más las mujeres que destacaron en todos los campos, mostrando su valía. Así, por ejemplo, en Italia, cabe citar nombres como Maria Gaetana Agnesi (1718-1799), matemática ilustre desde muy temprana edad; o la condesa Clelia Grillo Borromeo (16841777), matemática y científica, conocedora, según se decía, de todas las ciencias y todas las lenguas de Europa; o la astrónoma inglesa de origen alemán Caroline Lucrecia Herschel (1750-1848); o la francesa Gabrielle-Émilie Le Tonnelier de Breteuil, marquesa de Châtelet (17061749), amante de Voltaire y de notable inteligencia, adepta de los cafés parisinos más relevantes, de los salones y de los cenáculos científicos; o la médica alemana Dorothea Christiane Leporin Erxleben (1715-1762), por citar solo algunas representativas.

Asimismo, una vez casadas, eran libres de ejercitar cierto dominio en sus propias casas; pudiendo influir, incluso, en las decisiones de sus esposos. Buena parte de ellas tuvo también la ocasión de organizar frecuentes encuentros en sus salo- 
nes con numerosos intelectuales de los más variados lugares y culturas. De este modo, continuarán la arraigada tradición de los salones literarios femeninos, ya iniciada en el siglo anterior, pero ampliando los temas de debate, pues, si bien antes dedicaban sus encuentros, fundamentalmente, a intercambiar ideas sobre temas culturales y de sociedad, ahora también comenzarán a considerar, de manera cada vez más intensa, la política, argumento en el que la mujer difícilmente había podido entrar hasta entonces ${ }^{3}$.

Por lo que se refiere a las mujeres de las clases menos privilegiadas, si bien estuvieran imposibilitadas de recibir cualquier tipo de instrucción, al igual que sus maridos, estas pudieron aprovecharse, sobre todo en las ciudades, de la práctica cada vez más extendida del trabajo femenino; siendo cada vez más las que, además de ocuparse de sus labores domésticas y de sus hijos, se dedicaban también a trabajar fuera de casa en las más diferentes profesiones (criadas, costureras, lavanderas, peluqueras, comerciantes...), lo cual les permitía cierta autonomía más allá de las paredes de su hogar.

La mujer de la llustración, por tanto, por lo general, está ya mucho más instruida que sus antepasadas, es más independiente y autónoma y siente la necesidad de participar en la sociedad sin ser excluida de esta. En particular, las mujeres de clase alta serán grandes lectoras de tratados de educación, revistas, libros de historia, escritos filosóficos y científicos, e, incluso, algunas también de novelas. En sus salones, se rodean de literatos, científicos, filósofos, nobles y burgueses, de todas

3. Para profundizar sobre los salones literarios femeninos, recomiendo el interesante estudio de Maria Luisa Betri y Elena Brambilla (2004). las nacionalidades, y dirigen las charlas, animando las discusiones y ejerciendo su influencia sobre sus huéspedes, porque con su amplia cultura ya están capacitadas para ello. De este modo, tendrán la ocasión de participar en la vida pública, influyendo, indirectamente, con su pensamiento y sus opiniones, en la transformación de la sociedad y en la política de sus países; y demostrando, cada vez más, sus capacidades a muchos intelectuales que las apoyarán y defenderán ante los muchos misóginos aún existentes. Los salones serán, por tanto, importantes lugares de promoción para las mujeres; pudiendo considerarse una de las primeras señales de la progresiva evolución en las relaciones entre los dos sexos.

Asimismo, muchas mujeres querrán hacer públicas sus inquietudes y su pensamiento y, deseosas de darse a conocer, redactarán cada vez más textos, fundamentalmente, en modo de apuntes, diarios, opúsculos, y, hasta, incluso, las más cultas y atrevidas, escribirán ensayos sobre las más diferentes disciplinas; siendo cada vez mayor el número de publicaciones femeninas que verá la luz en toda Europa. Gracias a ello, a la vez que seguirán siendo criticadas y vituperadas por muchos misóginos, también serán elogiadas, apreciadas y seguidas por otros muchos varones que, en mayor número, se convencerán de los méritos de estas y de lo lejos que estaban de la verdad las acusaciones que durante siglos se habían vertido contra ellas.

Por su parte, también las mujeres de las clases populares tendrán una presencia cada vez más activa en la sociedad, participando en primera fila en las numerosas revueltas de la época, capitaneando y organizando muchas de estas, y llegando, en ocasiones, a ser las más violentas de 
entre los revolucionarios; incitando a los hombres a manifestarse junto a ellas.

En algunos países como Francia, las mujeres asistirán a las asambleas políticas, participando activamente en ellas; y, en muchas ocasiones, se manifestarán en la calle a favor de las ideas revolucionarias. También formarán clubes femeninos en los que se leen periódicos, decretos de la Asamblea, se discute de política e, incluso, se informa a los representantes de la Nación de las opiniones y propuestas allí presentadas.

La educación y la cada vez más prominente presencia de las mujeres en la vida pública, aunque aún, salvo raras excepciones, se las excluyera de la política y del poder, les habían dado fuerzas para unirse en la lucha, pues cada vez eran más las que, de una manera u otra, habían logrado la autonomía e independencia adecuadas para sacar valor y defender sus derechos; desmintiendo aquella imagen que de ellas daba la tradición misógina, al mostrarlas como seres inferiores, superficiales, locas y peligrosas; e insistiendo, entre otros muchos derechos fundamentales, sobre la importancia de la instrucción, imprescindible y necesaria para desarrollar y asegurar su independencia.

El espíritu revolucionario y progresista del siglo XVIII, promovido por el pensamiento ilustrado, había penetrado también en las mujeres, que anhelaban ansiosas la llegada de un giro definitivo que culminase en una transformación radical de la sociedad, donde, finalmente, hubiera cabida para ellas en igualdad de condiciones con respecto a los hombres. La situación así lo requería y, esperanzadas, confiaban en obtener pronto sus logros.

\section{La Declaración de los derechos del hombre y del ciudadano y la exclusión de las mujeres como ciudadanas a pleno derecho}

El período de la llustración supuso numerosos avances en las sociedades capitalistas, tras intensas y largas luchas y reivindicaciones a favor del derecho natural de los hombres, de reformas sociales adecuadas a los nuevos tiempos, del contrato social y de las libertades para todos los individuos sin distinción de clases, sostenidas por numerosos pensadores de gran envergadura que, con su pensamiento, llamaban a la acción a todos los hombres. Todo ello culminará con la Revolución Francesa y la proclamación de igualdad, libertad y fraternidad, pilares fundamentales del nuevo orden que estaba por constituirse y contenidos en la Declaración de los derechos del hombre y del ciudadano, aprobada en París, el 26 de agosto de 1789, por la Asamblea nacional constituyente, e inspirada en la declaración de independencia estadounidense de 1776 y en el espíritu filosófico del siglo XVIII. En este cuerpo normativo se fijarán los 17 artículos que, a partir de aquel momento, protegerán a los ciudadanos, reconociendo la igualdad de todos los seres humanos ante la ley y la justicia y defendiendo los derechos "naturales, inalienables y sagrados" de estos, como la libertad, la propiedad, la seguridad, la resistencia a la opresión; derechos que todos los hombres poseen por naturaleza y que ningún estado puede eliminar o limitar (González, 2018: 102-103).

Estas ideas revolucionarias supusieron un halo de esperanza para las mujeres que, 
gracias a los principios establecidos en aquel anhelado código, vieron cercana la posibilidad de ser incluidas, finalmente, en la sociedad en calidad de ciudadanas a pleno título. Sin embargo, nada iría más lejos de la realidad, pues, sorprendentemente, la tan aclamada Declaración de los derechos del hombre y del ciudadano excluía de la esfera de tales derechos a las mujeres, dirigiéndose al hombre en el sentido literal del término y no al ser humano en general, como habría supuesto la lógica, tras tantos años de progresos y de luchas por un fin común protagonizadas por ambos sexos.

Semejante agravio se sostenía no solo en la arraigada tradición que secularmente había excluido siempre a las mujeres del ámbito político y social, sino, de manera particular, en las teorías de los principales pensadores y políticos que encabezaron el movimiento y que, contra todo pronóstico, fueron los promotores de la misoginia más lacerante. A este respecto, resulta sumamente contradictorio que, precisamente, muchos de los protagonistas más relevantes en la construcción de lo que hoy conocemos como "derechos humanos" -figuras tan destacadas como Jean Jacques Rousseau, Denis Diderot o Voltaire- hayan sido, a su vez, grandes misóginos, que se mostraron acérrimos enemigos de las mujeres, negándoles cualquier tipo de derecho o privilegio, pretendiendo relegarlas, nuevamente, al espacio doméstico, reafirmando su sumisión a la autoridad masculina y frenando los logros que habían conquistado hasta aquel momento. Para ello, se fundamentaban en las milenarias acusaciones emitidas contra las mujeres y en las teorías misóginas de algunos de los grandes filósofos de la tradición que sostenían la idea preconcebida de que la naturaleza física de estas las hacía inferio- res a los hombres, basándose en el principio tota mulier est in utero ("toda mujer consiste en el útero").

Según dicha tesis, a diferencia del hombre, la mujer está inevitablemente condicionada por su constitución biológica, dominada y determinada por su útero y no por la razón. Por este motivo es débil, sensible y tendente a una imaginación desenfrenada que le impide madurar las ideas. Por otra parte, los males propios de su naturaleza la convierten en una eterna enferma con pocas posibilidades de conducir una vida social plenamente activa; estando predestinada al rol de la maternidad, debido a su constitución anatómica, única función posible para su género. Por ello, como concluía Rousseau, en su tratado filosófico Emilio, o De la Educación (1762), concretamente en el capítulo V, dedicado a Sofía o la mujer, según la ley natural, no siendo aptas las hembras más que para asumir su rol de madres, al ser excesivamente débiles, su mejor función es agradar a sus esposos, a cuyo servicio han de someterse bajo el yugo de su protección y su fortaleza física:

En la unión de los sexos, concurre cada uno por igual al fin común, pero no de la misma forma; de esta diversidad surge la primera diferencia notable entre las relaciones morales de uno y otro. Uno debe ser activo y fuerte, el otro pasivo y débil: es totalmente necesario que uno quiera y pueda; basta que el otro resista poco. Establecido este principio, de él se sigue que la mujer está hecha especialmente para agradar al hombre; si el hombre debe agradarle a su vez, es una necesidad menos directa, su mérito está en ser fuerte. Convengo en que no es ésta la ley del amor, pero es la de la naturaleza, que es anterior al amor (Rousseau, 1998: 535).

Según el pensador francés, cada sexo posee las funciones requeridas por la natu- 
raleza: el hombre las funciones públicas y la mujer las privadas; y estas, sostiene, no se pueden confundir ni intercambiar, si se quiere evitar una subversión. Asimismo, afirma, "el sostener de una manera vaga que son iguales los dos sexos y que tienen las mismas obligaciones es perderse en manifestaciones vanas, sin decir nada que no se pueda rechazar" (Rousseau, 1998: 523). Por este motivo, según sus tesis, tampoco su educación ha de ser igual, oponiéndose a que estas pudieran formarse del mismo modo que los hombres, en pro del beneficio común:

Demostrado que ni el hombre ni la mujer están ni deben estar constituidos del mismo modo en lo que respecta al carácter y al temperamento, se infiere que no se les debe dar la misma educación. Siguiendo las directrices de la naturaleza, deben obrar acordes, pero no deben hacer las mismas cosas; el fin de sus tareas es común, pero son diferentes, y, por consiguiente, los gustos que las dirigen. Habiendo procurado formar el hombre natural, por no dejar la obra imperfecta, veamos también cómo debe formarse la mujer para que le convenga al hombre. [...]

Cultivar en la mujer las cualidades del hombre y descuidar las que les son propias, es trabajar en detrimento suyo. Demasiado lo ven las astutas para dejarse engañar; cuando procuran usurpar nuestras ventajas, no abandonan las suyas, pero ocurre que no pudiendo amalgamar bien las unas con las otras, debido a que son incompatibles, no llegan con unas adonde hubieran alcanzado y con las otras no pueden competir con nosotros, perdiendo de esta forma la mitad de su valor. Hacedme caso, madres juiciosas; no hagáis a vuestra hija un hombre de bien, que es desmentir a la naturaleza; hacedla mujer de bien, y así podréis estar segura de que será útil para nosotros y para sí misma (Rousseau, 1998: 548).
Asimismo, el filósofo Diderot -por citar otro caso más de las muchas manifestaciones en contra del sexo femenino-, si bien en ciertas ocasiones y en determinados aspectos se mostró partidario de las mujeres 4 , las calificaba como "unos niños verdaderamente extraordinarios", con una imaginación infantil, incontrolable y peligrosa. Por otra parte, fue uno de los creadores de la primera edición de la Enciclopedia (1751-1772), obra más representativa de la llustración, en la que se definía el término "ciudadano" como un sustantivo dirigido exclusivamente a los hombres, reputando a las mujeres y los niños ciudadanos solo en calidad de miembros de la familia de un hombre:

[Ciudadano] aquel que es miembro de una sociedad libre de varias familias, que comparte los derechos de esta sociedad y que se beneficia de sus franquicias [...] Solo se otorga ese título a las mujeres, a los niños jóvenes, a los sirvientes en tanto miembros de la familia de un ciudadano propiamente dicho; pero no son verdaderamente ciudadanos (Diderot, 1753: 3488).

También Voltaire nos sorprende, al ser, quizá, uno de los ilustrados más progresistas, con afirmaciones sobre la mujer como las siguientes, corroborando el pensamiento de Rousseau y de muchos de sus contemporáneos:

4. De manera especial, a raíz de su relación amorosa con la escritora Louise-Henriette Volland, conocida como Sophie Volland -nombre derivado del griego antiguo, "sofia" (sabiduría), que le había atribuido el propio Diderot por la inmensa cultura que esta poseía. Interesante al respecto son las cartas que el filósofo le escribió a su amante, Lettres à Sophie Volland (1759-1762), en las que, además de manifestar el profundo amor que sentía por ella, así como su pensamiento filosófico, hará un examen de conciencia sobre algunos de sus postulados. 
No debe sorprender que en todas partes el hombre haya sido señor de la mujer, fundándose en la fuerza casi todo lo del mundo. Además, ordinariamente, el hombre es superior a la mujer en el cuerpo y en el espíritu. Han existido mujeres sabias, como han existido mujeres guerreras; pero nunca hubo mujeres inventoras. Han nacido para agradar y para ser el adorno de las sociedades; y parece que hayan sido creadas para suavizar las costumbres de los hombres (Voltaire, 1764: 247).

Creer en la perfección de la especie humana y en el progreso de su mente son algunos de los fundamentos del pensamiento ilustrado; sin embargo, la mujer no tenía cabida en este, puesto que, al estar completamente determinada por su fisiología, que es inmutable, su razón y sus funciones no evolucionan. Asimismo, frente a la tan defendida individualidad de los varones, para la mayoría de pensadores ilustrados, las mujeres pasaron a considerarse hembras de la especie humana, pertenecientes todas a un mismo colectivo, de naturaleza idéntica, y, por tanto, iguales entre sí; generalizando, bajo esta tesis, todos los rasgos que de ellas consideraban menospreciables.

Esta plétora de injurias y desprestigios reiterados por tantos hombres influyentes de la época, que llevarán a la completa exclusión del género femenino de los derechos del ciudadano, desencadenará una inmediata revolución entre las mujeres, que se rebelarán contra tamaña injusticia, enfurecidas e indignadas, al ver cómo se ponían en riesgo los avances que, finalmente, estaban logrando. Por ello, ahora ya, en su mayoría, mejor preparadas que sus antecesoras y tras tantos años de lucha por la anhelada igualdad entre seres humanos, sostenida cada vez por más hombres, comenzarán a tomar conciencia de sí mismas y de sus capacidades y se unirán en una intensa batalla para reclamar sus derechos, en un movimiento sin igual que se extenderá por toda Europa y Estados Unidos y que será decisivo para el progreso femenino y los avances obtenidos hasta nuestros días. De este modo, al igual que en la querella de las mujeres iniciada en el Renacimiento, pero, esta vez, de forma más incisiva y solicitando reivindicaciones hasta entonces impensables, iniciarán una intensa campaña dialéctica en defensa de una verdadera igualdad entre hombres y mujeres, según dictaban los Derechos del hombre y del ciudadano, exigiendo sus derechos como ciudadanas a pleno efecto 5 .

Estas valientes mujeres, que contribuyeron de manera determinante en los logros del colectivo femenino, pese a los muchos obstáculos a los que hubieron de enfrentarse, quisieron ser escuchadas con la fuerza que les daba tener razón y el sentirse arropadas por sus semejantes. $Y$ con sus mejores armas: sus voces y sus plumas, no cesarán en su empeño, sin temor a realizar actos para luchar por sus ideales que, en algunas ocasiones, las llevarán, incluso, a la muerte. (González, 2018: 104).

Podríamos citar a muchas mujeres representativas en esta larga batalla; sin embargo, nos detendremos solo en algunas de las más relevantes, para dar una visión

5. Interesante al respecto es la edición preparada por Alicia H. Puleo, La Ilustración olvidada. La polémica de los sexos en el siglo XVIII (1993). En cuanto a las reacciones en la Italia de la Ilustración contra la exclusión de las mujeres de la esfera de los derechos del ciudadano, véase: Mercedes González de Sande, "Las mujeres en la Italia del siglo XVIII: el largo camino hacia la conquista de sus derechos" (2018), del que hemos extraído algunas informaciones aquí presentadas. 
de conjunto sin extendernos demasiado en el argumento, sin duda, demasiado amplio para detallarlo en un solo estudio. Entre ellas, cabe señalar a la escritora y activista política Olympe de Gouges (pseudónimo de Marie Gouze), que, en 1791, tan solo dos años después de la proclamación de los Derechos del hombre y del ciudadano, publicó, en Francia, una réplica de estos, con el título homónimo: Declaración de los derechos de la mujer y de la ciudadanía, adaptándolos a la condición femenina. En su escrito, siguiendo el guion del primero, de Gouges reivindicaba la igualdad de derechos entre seres humanos y la consiguiente inclusión de las mujeres en las diferentes normativas aprobadas por la Asamblea; reconociéndolas como ciudadanas a todos los efectos.

Dedicando la obra a la reina María Antonieta, a la que Olympe consideraba tan oprimida como las demás mujeres, pretendía hacer una llamada a todas las de su género, pero también a los hombres que quisieran escucharla, para que se concienciaran de la injusticia que contra ellas se estaba cometiendo y se unieran en la lucha a favor de la igualdad entre ambos sexos; como sostendrá en el epílogo de su obra:

Mujer, despierta; el rebato de la razón se hace oír en todo el universo; reconoce tus derechos. El potente imperio de la naturaleza ha dejado de estar rodeado de prejuicios, fanatismo, superstición y mentiras. La antorcha de la verdad ha disipado todas las nubes de la necedad y la usurpación. El hombre esclavo ha redoblado sus fuerzas y ha necesitado apelar a las tuyas para romper sus cadenas. Pero una vez en libertad, ha sido injusto con su compañera. ; ¡Oh, mujeres! ¡Mujeres! ¿Cuándo dejaréis de estar ciegas? ¿Qué ventajas habéis obtenido de la Revolución? Un desprecio más marcado, un desdén más visible... ¿Qué os queda entonces?, la convicción de las injusticias del hombre (De Gouges, 1791).

De Gouges, en su Declaración, además de reivindicar los mismos derechos sociales, laborales y políticos concedidos a los hombres tras la Revolución Francesa, iba más allá con sus propuestas, proponiendo reformas radicales y revolucionarias hasta el momento nunca exigidas para las mujeres. Y así comenzaba el preámbulo de su manifiesto, casi idéntico a la Declaración de los Derechos del hombre:

Las madres, hijas, hermanas, representantes de la nación piden que se las constituya en Asamblea Nacional. Por considerar que la ignorancia, el olvido o el desprecio de los derechos de la mujer son las únicas causas de los males públicos y de la corrupción de 105 gobiernos, han resuelto exponer en una declaración solemne, los derechos naturales, inalienables y sagrados de la mujer a fin de que esta declaración, constantemente presente para todos los miembros del cuerpo social les recuerde sin cesar sus derechos y sus deberes, a fin de que los actos del poder de las mujeres y los del poder de los hombres puedan ser, en todo instante, comparados con el objetivo de toda institución política y sean más respetados por ella, a fin de que las reclamaciones de las ciudadanas, fundadas a partir de ahora en principios simples e indiscutibles, se dirijan siempre al mantenimiento de la Constitución, de las buenas costumbres y de la felicidad de todos.

En consecuencia, el sexo superior tanto en belleza en coraje, como en los sufrimientos maternos, reconoce y declara, en presencia y bajo 105 auspicios del Ser Supremo, los Derechos siguientes de la Mujer y de la Ciudadana (De Gouges, 1791).

Entre sus muchas reivindicaciones, la más revolucionaria fue, sin lugar a duda, la que sugería la abolición del matrimonio a favor de un contrato social entre los cón- 
yuges en paridad de derechos. Asimismo, dirigió el periódico L'Impatient, que reivindicaba la condición femenina, y fundó la "Société populaire des femmes".

Muy activa en la política, además de reivindicar los derechos de las mujeres, paralelamente, criticó y censuró públicamente la represión jacobina, enfrentándose al mismo Robespierre, por lo que fue acusada de reaccionaria y guillotinada en 1793. Triste final para una mujer valiente que, con su pluma y con sus actos, contribuyó ampliamente a la toma de conciencia y al progreso de las mujeres.

Casi de forma contemporánea, en Inglaterra, podemos destacar a una mujer considerablemente representativa y de entre las más notables en la causa a favor de la condición femenina: la escritora Mary Wollstonecraft, que, un año después de la escritora francesa y con una extensión más amplia, en 1792, publicó la Vindicación de los Derechos de la Mujer. En esta, entre otras cuestiones, pidiendo justicia para la mitad de la raza humana, reivindicaba el derecho al trabajo y a la emancipación económica de las mujeres, defendiendo, además, la suma importancia de su acceso a una educación apropiada y en paridad de condiciones con los hombres. Única causa, unida a la falta de medios para moverse del mismo modo que los varones en la sociedad, que las hacía parecer inferiores a estos sin serlo, $y$, en ocasiones, incluso "estúpidas y superficiales". Asimismo, abogaba por una escolarización mixta, para que hombres y mujeres fueran educados según el mismo modelo. Reproducimos, a continuación, algunas citas de la Vindicación, representativas para ilustrar su pensamiento:

Fortalezcamos la mente femenina ensanchándola y será el final de la obediencia cie- ga; pero como el poder busca la obediencia ciega, los tiranos y los sensualistas están en lo cierto cuando tratan de mantener a la mujer en la oscuridad, porque el primero sólo quiere esclavos y el último un juguete (Wollstonecraft, 1792: 22).

Para hacerlas débiles y lo que algunos pueden llamar bellas, se descuida el entendimiento y se fuerza a las niñas a sentarse quietas, jugar con muñecas y escuchar conversaciones vanas (Wollstonecraft, 1792: 73).

La escritora inglesa se lamenta, en su tratado, de las limitaciones que la falta de educación supone para las mujeres, quienes, en muchas ocasiones, deseosas de agradar a los hombres y sin ninguna formación, se preocupan solo de su aspecto físico, careciendo de cualquier otra inquietud; de ahí que se las considere, con cierta razón, estúpidas y superficiales:

Al sostener los derechos por los que las mujeres deben luchar en común con los hombres, no he intentado atenuar sus faltas, sino probar que eran la consecuencia natural de su educación y su posición en la sociedad. Si es así, es razonable suponer que su carácter cambiará y se corregirán sus vicios cuando se las permita ser libres en un sentido físico, moral y civil (Wollstonecraft, 1792: 182).

Por ello, Wollstonecraft reivindica la necesidad de la instrucción femenina, sin la cual permanecerán siempre encerradas en sus jaulas, sin libertad y sin obtener nunca una realización plena; atrofiando sus mentes y eximidas de toda posibilidad de descubrir el mundo y de demostrar su valía:

Enseñadas desde su infancia que la belleza es el cetro de las mujeres, la mente se amolda al cuerpo y, errante en su dorada jaula, sólo busca adornar su prisión. [...] Confinadas en jaulas como la raza emplumada, no tienen nada que hacer sino acicalarse el 
plumaje y pasearse de percha en percha. Es cierto que se les proporciona alimento y ropa sin que se esfuercen o tengan que dar vueltas; pero a cambio entregan salud, libertad y virtud (Wollstonecraft, 1792: 49).

Según ella, las mujeres carentes de una educación adecuada, "presas de sus sentidos", son incapaces de pensar racionalmente; perjudicándose, con ello, no solo a sí mismas, sino también a toda la sociedad, contribuyendo a la destrucción de esta y frenando su progreso:

Así pues, me aventuraré a afirmar que hasta que no se eduque a las mujeres de modo más racional, el progreso de la virtud humana y el perfeccionamiento del conocimiento recibirán frenos continuos. Y si se concede que la mujer no fue creada simplemente para satisfacer el apetito del hombre o para ser la sirvienta más elevada, que le proporciona sus comidas y atiende su ropa, se seguiría que el primer cuidado de las madres o padres que se ocupan realmente de la educación de las mujeres debería ser, si no fortalecer el cuerpo, al menos no destruir su constitución por nociones erróneas sobre la belleza y la excelencia femenina; y no debería permitirse nunca a las jóvenes asimilar la noción perniciosa de que un defecto puede, por cierto proceso químico de razonamiento, convertirse en una excelencia (Wollstonecraft, 1792: 183).

Como harán otras muchas mujeres de su época, la autora aprovecha, en su obra, para hacer un llamamiento a los hombres sensatos para que comprendan sus reivindicaciones y las ayuden a romper las cadenas que las sometían tan injustamente, apoyándolas en su lucha por la igualdad, por el beneficio común de todos los seres humanos:

En mi opinión, son particularmente útiles los escritores que hacen que el hombre se compadezca del hombre, sin tener en cuen- ta la posición que ocupa o los ropajes de los sentimientos artificiosos. Por ello, me alegraría convencer a los hombres juiciosos de la importancia de algunos de mis comentarios y persuadirlos para que sopesen sin pasión todo el tenor de mis observaciones.

Apelo a sus entendimientos y, como una criatura semejante, reclamo, en nombre de mi sexo, cierto interés en sus corazones. Les suplico que ayuden a emancipar a sus parejas, para que se conviertan en sus compañeras. Si los hombres rompieran con generosidad nuestras cadenas y se contentaran con la camaradería racional en lugar de la obediencia servil, hallarían en nosotras hijas más obsequiosas, hermanas más afectuosas, esposas más fieles y madres más juiciosas; en una palabra, mejores ciudadanas. Entonces los amaríamos con afecto verdadero, porque aprenderíamos a respetarnos a nosotras mismas, y la paz mental de un hombre valioso no sería perturbada por la necia vanidad de su esposa, ni los niños se irían a cobijar a un pecho extraño, al no haber encontrado nunca un hogar en el de su madre (Wollstonecraft, 1792: 138-139).

Concluyendo su discurso y para incitar más a los varones a compartir su pensamiento, Wollstonecraft, haciendo uso de la ironía, cierra su Vindicación sosteniendo la idea de que para tener obligaciones hay que tener derechos; por lo que, si las mujeres carecían de derechos, tampoco habrían de estar sujetas a ningún tipo de deber, "pues derechos y deberes son inseparables":

Si se sostiene esta posición, las mujeres no tienen derechos inherentes que reclamar y, por la misma regla, sus deberes se desvanecen, pues derechos y deberes son inseparables. Luego sé justo, oh tú, hombre de entendimiento, y no señales con mayor severidad lo que hacen mal las mujeres que las tretas ariscas del caballo o del asno a los que proporcionas comida, y concede el privilegio de la ignorancia a quienes niegas los 
derechos de la razón, o serás peor que los capataces egipcios al esperar virtud donde la Naturaleza no ha otorgado entendimiento (Wollstonecraft, 1792: 182).

Otra de sus obras representativas, anterior a la Vindicación, fue Reflexiones sobre la educación de las hijas (1787), donde, a través de una especie de guía de comportamiento para las mujeres, insiste, nuevamente, en la importancia y necesidad de la instrucción femenina para el beneficio de la sociedad entera.

El pensamiento filosófico de Wollstonecraft, que sentará las principales bases del feminismo moderno, unido a su conflictiva vida personal, han influido ampliamente en numerosas obras de feministas posteriores; haciendo de esta relevante activista una de las más populares de la Europa de su época.

Tal y como anhelaba la escritora inglesa en sus Vindicaciones, cabe destacar el hecho significativo de que cada vez más hombres, escuchando los llamamientos de tantas mujeres, comenzaban a unirse a su causa, reivindicando para estas igualdad de derechos y ensalzando sus virtudes; contribuyendo ampliamente a la eliminación de los prejuicios contra el colectivo femenino y a su progresiva aceptación e incorporación en la esfera pública. En este sentido, fue relevante la figura de Marie Jean Antoine Nicolas de Caritat, marqués de Condorcet, filósofo y científico, diputado de la Asamblea Legislativa de la Convención, además de gran defensor de las mujeres. Destaca su ensayo Bosquejo de un cuadro histórico de los progresos del espíritu humano (1793), en el que solicitaba, con juiciosos razonamientos, la admisión de las mujeres al derecho de ciudadanía, el voto censatario, así como el acceso de estas a la educa- ción y al trabajo. Reproducimos algunos fragmentos representativos de su pensamiento, como mera muestra de las muchas manifestaciones de hombres sensatos que se irán uniendo en la intensa y ardua batalla en defensa de la igualdad entre seres humanos:

Entre los progresos más importantes del espíritu humano para conseguir el bienestar general, debemos contar con la total abolición de los prejuicios que han establecido la desigualdad de derechos entre los dos sexos, funesta incluso para el favorecido. Sería inútil buscar los motivos que la justifiquen en las diferencias de sus características físicas, en las fuerzas de la inteligencia, en su sensibilidad moral. Esta desigualdad no ha tenido más origen que el abuso de la fuerza, aunque después se haya tratado en vano de excusarla por medio de sofismas. [...] 0 bien ningún individuo de la especie humana tiene verdaderos derechos, o bien todos tienen los mismos derechos; y quien vota contra el derecho del otro, sea cual fuere su religión, su color o su sexo, reniega en ese mismo momento de los suyos (Condorcet, 1980: 247).

\section{La Breve difesa dei diritti delle Donne y la lucha por la iqualdad de género en la Italia de la llustración}

\section{3.l La llustración en Italia y el resurgimiento cultural de las mujeres}

El impulso de los ideales revolucionarios y el clima político de la campaña napoleónica, si bien con un ligero retraso con respecto a otros países, también se extenderá por toda la península itálica. 
El aparente aislamiento de Italia, marcada aún por el fuerte peso de la Contrarreforma y dividida en un conglomerado de ciudades-estado gobernadas por los poderes absolutos de la Iglesia, de principados hereditarios o de soberanos extranjeros -salvo las repúblicas de Génova y Venecia- no supuso un obstáculo para la introducción de las ideas ilustradas. Si bien la prensa italiana no gozaba de libertad de expresión para criticar a los diferentes gobiernos del territorio, sí estaba en condiciones para poder informar sobre los acontecimientos que tenían lugar fuera de las fronteras de este, en especial los que provenían de Francia; introduciendo, de este modo, todas las novedades del pensamiento y de la acción del espíritu progresista que iban calando cada vez más en el país. Asimismo, por toda la península, fue incrementándose la difusión clandestina de escritos que incitaban a la revolución, así como la formación de clubs conspiratorios y ciertas sociedades patrióticas en las que se defendían los ideales subversivos y se proyectaban diferentes formas de conspiración.

El sistema legal y administrativo de la Francia ilustrada y progresista fue visto por muchos italianos como modelo ideal contra el excesivo conservadurismo de Italia y el estancamiento de sus gobiernos, así como contra el fuerte peso de las élites tradicionales italianas, en beneficio de un colectivo mayor de ciudadanos que exigían numerosas mejoras a favor de su condición social, en igualdad de condiciones con respecto a las clases más privilegiadas.

Para frenar la difusión de las ideas revolucionarias provenientes del país vecino, que amenazaban potencialmente su estabilidad, los diferentes gobiernos italianos llevaron a cabo una rigurosa política de oposición y represión; procurando dar fin al incipiente reformismo por medio de duras persecuciones y represalias contra los revolucionarios más osados, restaurando, incluso, la pena de muerte. Por ello, a finales del siglo XVIII, debido a las drásticas medidas de los gobiernos italianos, muchos revolucionarios del país tuvieron que huir a Francia, donde se mantendrán activos, preparando el camino para una intervención francesa en la península itálica, en la que las tropas francas encontrarán un terreno abonado para aplicar las ideas de su país natal.

Sin embargo, en contraste con el atraso del sistema, resultó de especial relieve el sorprendente desarrollo cultural extendido por toda la península, fruto del esplendor renacentista del siglo anterior, que unía al país itálico en un fenómeno casi incomparable en el resto de Europa. De este modo, pese a que la concepción de Italia como nación aún no estaba muy afianzada, la idea de una república intelectual italiana se estaba reforzando de manera cada vez más intensa, gracias a un amplio y destacado colectivo de intelectuales de ambos sexos, tanto de la nobleza como de la alta y creciente burguesía, que interactuaban de manera muy proficua con la comunidad intelectual europea; haciendo de Italia un importante núcleo de erudición progresista y de una iluminada reforma social y cultural (González, 2015-2017: 166).

En este notable florecimiento cultural, iniciado en las últimas décadas del siglo XVII y llegado a su culmen a finales del XVIII, cabe señalar un considerable número de relevantes mujeres, especialistas en los más variados campos del saber, a los que pudieron acceder gracias a su privilegiado estatus social, que, unido a su extrema cultura, las hacía fuertemente influyentes en su nación. Estas destacadas intelectuales, altamente elogiadas y admiradas, 
dentro y fuera de sus fronteras, por sus encomiables virtudes, contribuyeron de forma determinante en el progreso de las mujeres italianas, pues, mirándose en ellas, cada vez serán más las que tomarán conciencia de los méritos y de las capacidades femeninas, así como de la posibilidad de superación de los innumerables obstáculos que la tradición misógina les había impuesto ${ }^{6}$.

Muchas de ellas, siguiendo a sus contemporáneas europeas, aprovechando su elevada formación y su fuerte influencia en la sociedad, se manifestarán y se opondrán, tanto por escrito como en numerosas manifestaciones públicas, a las injusticias cometidas contra su sexo; reivindicando la paridad de derechos entre hombres y mujeres, en una intensa batalla dialéctica que ya no tendrá fin y que se intensificará en el siguiente siglo hasta la consecución de los muchos logros actuales.

En este contexto, destacamos el tratado Breve difesa dei diritti delle Donne ${ }^{7}$, publicado en Asís, en 1794, y cuya desconocida autora -o autor- firma bajo el pseudónimo de Rosa Califronia ${ }^{8}$, supuesta condesa romana, que, con solo varios

6. Para profundizar al respecto, véase "El florecimiento cultural de las mujeres en el siglo XVIII italiano" (González, 2015-2017).

7. El tratado fue publicado en España con el título homónimo (Califronia, 2013), en su versión completa en español e italiano, acompañado de una introducción y una edición crítica de las que hemos extraído parte de la información aquí presentada, así como las citas en español de la obra.

8. Por lo que respecta a la autoría del tratado y las diferentes hipótesis sobre la identidad de la supuesta condesa romana escondida bajo el pseudónimo de Rosa Califronia, entre las que no se descarta la posibilidad de que esta fuera, en realidad, un varón, véase "La Breve difesa dei diritti delle Donne y algunas cuestiones sobre su autoría" (González, 2017). años de retraso con respecto a otros países, corroborará aquel movimiento colectivo iniciado en Europa de tantas mujeres valientes que se rebelaron contra la desoladora condición femenina en favor de sus derechos. Entre estas, las ya mencionadas Olympe de Gouges y Mary Wollstonecraft, quienes, indudablemente, influyeron en la redacción de la obra, como se puede deducir ya desde su propio título.

\subsection{Estructura y contenidos de la Breve difesa dei diritti delle Donne}

El tratado, cuyo objetivo principal era denunciar la contradictoria exclusión femenina de la esfera de los derechos humanos, tras la proclamación, en 1789, de la Declaración de los derechos del hombre y del ciudadano, así como la contemporánea pérdida de los privilegios que las mujeres habían ido adquiriendo, resultaba, en cierta medida, algo menos reaccionario y reivindicador que el de sus predecesoras europeas y más enlazado, en cuanto a estructura y contenido, con la querella de las mujeres iniciada por sus precursoras renacentistas -como Moderata Fonte, Arcangela Tarabotti o Lucrezia Marinelli, entre otras. De este modo, a diferencia de sus predecesoras europeas, sus reivindicaciones se mantienen, especialmente, en la esfera de la igualdad de derechos civiles, sin entrar apenas en pretensiones políticas; lo cual no resta para que el tratado sirva de referente óptimo para corroborar la extensión del fenómeno prefeminista por todo el panorama europeo.

Esta diferencia, probablemente, se debiera al profundo conservadurismo de la Italia de aquel período, fuertemente marcada por el pensamiento contrarreformis- 
ta y el imponente poder de la Iglesia -en especial en las zonas que se encontraban bajo el dominio de los Estados Pontificios-, que llevaría a la hipotética condesa a no pretender para el colectivo femenino mucho más que lo suficiente y tolerable en consonancia con la mentalidad de su tiempo. De ahí también que su autor o autora, aun moderando el tono y evitando cualquier vinculación con el espíritu ilustrado y revolucionario que pululaba por toda Europa, se ocultara bajo el anonimato para expresarse con cierta libertad, evitando posibles represalias. Un anonimato del que, asimismo, se valdrá para tomar la palabra en representación de todo el conjunto de mujeres y hombres que ansiaban transformar la sociedad, derribando la losa misógina que obstaculizaba el progreso femenino y erigiéndose en portavoz de estos sin adquirir ningún tipo de protagonismo. A este respecto, el pseudónimo escogido para realizar su cometido, Rosa Califronia, es altamente significativo, puesto que, siguiendo la etimología de las tres palabras que forman el nombre, quiere decir "conjunto de bellos pensamientos", como los que la autora muestra en su tratado con el propósito de defender a las mujeres y reivindicar una efectiva igualdad entre seres humanos. Del mismo modo, la etimología del nombre de la supuesta hermana que la acompaña y la ayuda aportando información para la elaboración de su obra, Polifronia ("muchos pensamientos"), podría hacer referencia a las muchas mujeres y hombres que sobre esta cuestión habían escrito a lo largo de los siglos, en el extenso debate de la querella de las mujeres, y que han influido, indudablemente, en la realización de la Breve defensa.

La Breve defensa de los derechos de las Mujeres, con una extensión cercana a las setenta páginas, está dividida en ocho capítulos, a los que se les dedica mayor o menor espacio según sea el peso del argumento tratado en cada uno de ellos. Estos, a su vez, están precedidos de una breve introducción en la que Rosa Califronia expone los motivos que la han empujado a escribir su tratado en defensa del colectivo femenino.

En su "Prefacio", la autora explica su intención de hacer una firme defensa de los tan aclamados derechos del hombre, entendido como ser humano, e incluyendo dentro de este género a las mujeres. Una representativa parte de la población que parece hayan querido olvidar aquellos varones que tanto festejaban los logros obtenidos tras sus incesantes luchas por la igualdad, a raíz de la Revolución Francesa. Y, con estas palabras, comienza su queja:

Se hacen públicos continuamente, con el favor de las imprentas, los filosóficos derechos del hombre; pero nunca se ve, en nuestros días, una obra razonada sobre los derechos de las Mujeres. ¿Sirve, acaso, decir que en el género de los hombres está también contenida la especie del sexo femenino? Los filósofos ponen en práctica los derechos de los varones; y la especie femenina no entra en éstos para nada. Baste echar un ligero vistazo al aciago teatro de Francia, donde, con gran clamor, se han ensalzado LOS DERECHOS DEL HOMBRE. ¡Cuántas alabanzas para el sexo viril! A las mujeres, a sus derechos, ¿qué sistema se les ha establecido? Es más, éstas han perdido, a causa de la anhelada igualdad, los títulos de familias ilustres, y las insignias gloriosas de su nobleza. Como mucho, las pescaderas han conseguido un mísero privilegio negativo de ser iguales a aquella clase popular de los hombres, los cuales, por su inmensa miseria, se han quedado sin sus culottes, mientras que, en Francia, las Mujeres de mediocre esfera llevaban ya calzones: y, a 
fin de cuentas, éste es un privilegio concedido por la filosófica asamblea también a los perros, a los gatos y a los simios. Hecho, pues, el justo análisis, han sido menospreciadas, en sustancia, las Mujeres, mientras se proclamaban, a voces y por todas partes, los privilegios y los derechos del hombre; y mientras se ha querido segar, con una hoz afilada, los más altos árboles para reducir todos los productos del campo a perfecta igualdad (Califronia, 2013: 48).

La autora, haciéndose portavoz y representante del género femenino, lleva a cabo una defensa en la que incluye a todas las mujeres en general; a diferencia de otras muchas intelectuales, que optaban por ensalzar, exclusivamente, a las figuras más representativas de la Historia, para demostrar las virtudes y los méritos de estas. De este modo, pretende eliminar "la acusación extraída del simple nombre de Mujer", como ella misma sostiene, argumentando los motivos que hacen a todas las hembras dignas de sus reivindicaciones:

[...] yo he considerado oportuno, a su vez, ofrecer una breve defensa de nuestro sexo en general, de manera que no se restrinja la alabanza a un determinado número de hembras y que no siga viva en nuestra especie la acusación extraída del simple nombre de Mujer. [...]

Demostraré, por tanto, la irracionalidad de las declamaciones masculinas contra nuestro sexo en general; y, libre de todo estudio partidario, así como confieso sus defectos, del mismo modo protegeré sus verdaderos derechos (Califronia, 2013: 67).

Califronia, con su Defensa, al igual que estaban haciendo tantas contemporáneas suyas en toda Europa, se propone desmentir todas las teorías en las que secularmente se habían apoyado tantos misóginos, y, siguiendo a estos, también los pensadores ilustrados, para desprestigiar a las mujeres y considerarlas inferiores a ellos. Infames teorías, que, con criterios sin fundamento, pretendían excluirlas de la esfera de los derechos del hombre, negándoles la categoría de ciudadanas, arrebatándoles cualquier tipo de privilegio y situándolas casi en el mismo nivel que los animales. Para ello, organizará los capítulos de su tratado basándose en las acusaciones más genéricas que, durante siglos y de un extremo al otro del mundo, se habían ido lanzando contra las mujeres para menospreciarlas y rebajarlas con respecto a los hombres. Acusaciones que, para el pesar de todas ellas, habían llevado a los varones ilustrados a negarles los tan aclamados derechos por los que tanto habían luchado.

De entre las muchas acusaciones emitidas contra las mujeres, la escritora italiana selecciona cinco, para elaborar sus seis primeros capítulos, que engloban, a su vez, todas las demás críticas infundadas sobre estas. Concretamente, y siguiendo el orden establecido por ella, en sus capítulos, las acusaciones que pretende desmentir con sus tesis son las siguientes: las mujeres, por naturaleza, carecen de razón; las mujeres son más débiles física e intelectualmente que los hombres; las mujeres están locas; las mujeres están llenas de vicios y, por consiguiente, son la causa de todo mal; las mujeres son ignorantes y soberbias. A esta última acusación le dedica dos capítulos, el $\mathrm{V}$ y el VI; presentando, además, en el sexto, a modo de demostración de sus tesis, una larga serie de nombres de mujeres intelectuales, sobre todo contemporáneas suyas, que, con su gran sabiduría, han demostrado destacar en la sociedad, por sus méritos y sus capacidades, en las más diferentes disciplinas. 
Cabe señalar el elevado número de mujeres ilustres que Califronia cita en su tratado para exaltar la excelencia femenina en los más variados campos, así como los prestigiosos roles que muchas desempeñaron a lo largo de la Historia: comenzando por la Virgen María, escogida por el Todopoderoso para ser la madre de su hijo, hasta llegar a otras destacadas mujeres, algunas de ellas apenas mencionadas en los documentos históricos, pero que demostraron, en su momento, con sus muchos conocimientos y su prestigio social, la inmensa valía de su colectivo. Como novedad a este recurso, tan utilizado tradicionalmente en la querella de las mujeres, de ensalzar a figuras femeninas relevantes del pasado, para demostrar la grandeza de las mujeres, Califronia aportará, además, una larga lista de contemporáneas suyas, prácticamente desconocidas en la actualidad, pero sobradamente destacadas en su tiempo por sus altas capacidades y sus encomiables méritos, que contribuirán altamente en el progreso femenino, desmintiendo, con su valía, las muchas injurias y acusaciones emitidas contra las de su sexo y subvirtiendo la malograda imagen que de ellas había difundido la tradición misógina.

Los capítulos VII y VIII los escribe a modo de conclusión de las tesis expuestas en los seis capítulos anteriores; sosteniendo, así, en el capítulo VII, una vez presentadas todas sus alegaciones anteriores, que las mujeres son más excelentes que los hombres por las muchas virtudes y méritos demostrados a lo largo de la Historia, pero también constatados en su breve tratado.

Por último, en el capítulo que cierra la obra, como tantas otras mujeres cultas reivindicarían durante siglos, insistirá en la importancia y en la necesidad de una instrucción apropiada para las mujeres, principal causa de las muchas acusaciones que a estas se les imputan, puesto que la ignorancia las vuelve débiles e inferiores. Por ello, reclama el derecho a una educación en igualdad de condiciones con los hombres, consciente de que la mejor y más preciada arma de la que pueden disponer los seres humanos para defenderse en la sociedad son sus propios conocimientos y la experiencia y la fuerza que les otorga el saber. Con este propósito, la supuesta condesa romana intentará involucrar a los varones en sus razonamientos, haciéndoles entender la utilidad de la educación femenina y solicitándoles encarecidamente que concedan el acceso de las mujeres a una formación adecuada, no solo por su propio beneficio, sino también por el de la sociedad entera y el buen funcionamiento de esta:

Educad, oh, señores varones, a vuestras hijas en los cultos estudios, en las bellas artes, y veréis el mundo cambiado; apenas veréis los vestigios de los vicios en el sexo femenino. Haced que su ingenio tenga el agradabilísimo objeto de las bellas artes y útiles ciencias; y la experiencia, al menos, os hará comprender que las hembras, amando los estudios, odiarán al padre de todos los vicios, es decir, el ocio, y emplearán con placer grandísimo sus afectos en el cultivo del intelecto, por ellas y por utilidad común. Ya siento de cerca el murmullo de quien desaprueba en las Mujeres el estudio. Esto es un error casi común en los hombres; por eso merecéis compasión. Pero el error no tiene el derecho de prescripción, y, mucho menos, de usucapión por su antigüedad y por su extensión (Califronia, 2013: 173, 175).

Por otra parte, acusa duramente a los hombres de ser los directos responsables de la ignorancia de estas - de la que derivan la mayoría de sus supuestos males y defectos-, por haberles impedido, du- 
rante siglos, la posibilidad de formarse; lo cual es esencial para el desarrollo del intelecto y para el crecimiento del ser humano:

Si en alguna nación más que en otra están las hembras privadas de cultivo de ingenio la culpa es vuestra, oh, mis señores varones, que, teniendo el dominio de la familia, y temiendo el sutil y penetrante ingenio de las Mujeres, muchos, demasiado avaros ahorradores, empleáis a las hijas en el vil encargo de criadas (Califronia, 2013: 173).

El imperio [...] que ejercen los hombres sobre las Mujeres, imperio prepotente y tiránico, es el que las condena a estar lejanas de la culta literatura (Califronia, 2013: 187).

Asimismo, acusa de necedad a quienes atacan a las mujeres por ser más torpes y débiles de ingenio, puesto que son, precisamente, ellos mismos los culpables de tales defectos, que no existirían si les consintieran una adecuada formación:

Crece, además, el oprobio de esta acusación si se quiere observar la causa del hecho por el que las Mujeres son consideradas comúnmente más torpes y débiles de ingenio; [...] ¿Quién es el Legislador y el Gobernador de una familia sino un varón? ¿Quién ordena y dirige las operaciones de ésta sino el hombre? El varón, pues, dirige a las hembras de su casa completamente lejos del cultivo de ingenio; ¿y pretende éste que produzcan frutos de talento? [...] Ésta es una verdadera arrogancia de máxima temeridad, o de igual estulticia. Que no cultive el viñador, por ejemplo, las fresas, o las alcachofas, según el sistema común de los peritos en este arte; que abandone estas plantas a la discreción del inculto terreno; y pretenda a la vez que den óptimos frutos. Éste, dirán todos, o es un necio que no sabe que el cultivo es necesario para los frutos, o bien es un loco, que pretende los efectos sin poner los medios; y, finalmente, éste es el loco de los locos, pues reprocha en una planta un defecto del que sólo él es la verdadera causa (Califronia, 2013: 91, 93).

Califronia es consciente de que muchos males de la sociedad son debidos a la extrema ociosidad y a la ignorancia de muchas féminas. Sin embargo, según sostiene, estos males tendrían fácil solución si, al igual que a los hombres, se les permitiera también a ellas el acceso a la educación y el derecho a una formación digna en todos los campos necesarios del saber. En especial, en aquellos en los que estas demuestren tener talento, puesto que disponen, por naturaleza, de las mismas capacidades que los hombres para aplicarse en los estudios:

por fin, aprenda Italia y toda Europa, nuevamente, a conocer útilmente la capacidad natural del ingenio femenino; $y$, por ello, en vez de mantener a muchas en una vida demasiado ociosa y perniciosa para las propias Mujeres y para toda la sociedad civil cristiana, las sepa educar en aquellas ciencias que son útiles y necesarias primeramente para la felicidad de la salud física, de la moral y de la económica; y, por consiguiente, conforme a la variedad de sus talentos, emplearlos en otros estudios de gran utilidad. Así desaparecerán del Mundo al menos la mitad de los males físicos y morales, causados por el ocio de las Mujeres debido a la triste educación que a éstas se les da en Europa (Califronia, 2013: 129, 131).

[...] No hay, por tanto, razón alguna para negarles a las Mujeres aquel estudio que al hombre se le concede; existiendo en éste y en aquéllas las mismas propiedades naturales, oportunas para el estudio (Califronia, 2013: 181).

De capítulo en capítulo, Rosa Califronia expondrá cada una de las acusaciones contra las mujeres más reiteradas en todos los tiempos y culturas, así como las 
motivaciones que los misóginos alegan para convertirlas en el sexo inferior; reinterpretándolas desde una óptica femenina y desmintiéndolas con argumentaciones bien razonadas y fundamentadas, bien por medio de los muchos conocimientos que le proporciona su gran cultura y su propia experiencia, bien basándose en textos acreditados. En especial, las Sagradas Escrituras, ciertos textos poéticos, o ensayos y tratados escritos por intelectuales con criterio ${ }^{9}$, que, en diferentes épocas de la historia, se han manifestado en defensa del colectivo femenino, a quienes la supuesta condesa romana no se cansará de citar a lo largo de su obra, para

9. A este respecto cabe señalar la amplia bibliografía que la escritora aporta, en el capítulo V, sobre obras de numerosos autores que, desde el siglo XVI hasta el XVIII, defendieron y ensalzaron las virtudes de las mujeres, apoyándolas y elogiando su valía y sus destacables méritos. Las más de cincuenta obras mencionadas en el tratado, en las que intelectuales varones de diferentes nacionalidades rinden homenaje a un amplio elenco de mujeres que han sobresalido en los más variados campos del saber -filósofas, médicas, matemáticas, militares, literatas, artistas, reinas, princesas, emperatrices...- es, además, una buena demostración de la inmensa cultura de la autora y de las muchas lecturas que ha realizado. Asimismo, supone una valiosa corroboración del apoyo que muchos hombres sensatos brindaron a las mujeres durante siglos; si bien, al igual que a ellas, el pensamiento misógino predominante en la historia no los tomara en consideración, desdeñando sus juicios. Este dato significativo nos podría también llevar a la conclusión de que, tal vez, quien se oculte tras la falsa identidad de Rosa Califronia sea del sexo masculino y no una mujer, especialmente por la cantidad de nombres de varones que incluye en su tratado; un listado sin igual hasta entonces en ninguna otra obra escrita a favor de las mujeres; casi como si, de este modo, quisiera justificar su defensa, pese a ser hombre, haciendo partícipes a otros muchos varones que pensaban como él y sintiéndose así arropado por estos. (González, 2017: 34-35) corroborar sus tesis, agradeciendo la gran labor que ejercieron en favor de la causa de las mujeres.

No es de extrañar que su principal fuente de documentación y confrontación para defender sus razonamientos sean los textos bíblicos, puesto que estos siempre habían sido los de más fácil acceso para las mujeres durante el curso de la historia. Por otra parte, milenariamente, habían sido, y eran, la principal fuente de inspiración en la que se fundamentaban las principales teorías de la tradición misógina, que partían de la perenne idea de que el pecado original fue provocado a causa de una mujer, por cuya culpa se desencadenará una larga serie de males en la humanidad. Por ello, basándose también en las mismas fuentes, Califronia elaborará sus argumentaciones en defensa de las mujeres, realizando una nueva interpretación de las Escrituras y de los demás textos tomados como referencia por los enemigos del género femenino que desmentía y subvertía por completo la ofrecida por el pensamiento misógino.

Así, por ejemplo, contra la teoría que sostenía que la mujer era inferior al hombre por haber sido creada después de este, ella rebatirá el hecho de que, si bien la mujer fue creada en segundo lugar, esta fue originada de la carne humana, mientras que el hombre nació del barro, materia mucho más inferior que la originadora de la mujer:

siendo yo amiga de la verdad, antepongo desde el principio el hombre a la mujer por el origen de éste. Fue él creado el primero por las manos del Todopoderoso; y la Mujer fue creada súbdita de éste, para que, una vez creada, le sirviera de ayuda. Sin embargo, hay, en esta misma creación una compensación para la especie femenina. El 
hombre fue creado del barro, y la Mujer fue creada de la carne humana. Así como es más noble la naturaleza de la carne que la del barro, igualmente ha de considerarse más noble el origen de la hembra, que, si bien no ha nacido naturalmente desde el principio como el hombre, también ella, y más noblemente, está formada de la todopoderosa mano creadora (Califronia, 2013: 151).

Aprovecha también, en su obra, para desmentir, además de a todos los varones que las acusan en general, a algunos hombres concretos, que, durante siglos, con sus falsas acusaciones, han influido en la mentalidad de otros muchos -pero también de muchas mujeres-, aumentando el desprecio y el ensañamiento contra estas. Entre estos, arremete contra Giuseppe Passi Ravennate y su tratado I donneschi difetti, publicado en Venecia, en 1599, y reeditado en 1605, que ilustraba 34 defectos, según él, propios e irreversibles del sexo femenino; en contra del cual ya se habían manifestado otras mujeres representativas en la historia del feminismo italiano, como sus prestigiosas precursoras Lucrezia Marinelli y Arcangela Tarabotti ${ }^{10}$.

Asimismo, acusará a los misóginos de caer en continuas contradicciones y de defender teorías que no tienen dónde sostenerse. Solo por el simple hecho de criticarlas, afirma nuestra autora, estos pecan continuamente de exceso de arrogancia y de falta de reflexión a la hora de formular sus infundados juicios; como

10. Véase al respecto las siguientes ediciones: Lucrezia Marinelli Vacca, De la nobleza y excelencia de las mujeres (edición y traducción de Antonella Cagnolati y Mercedes González de Sande, Sevilla, Arcibel, 2013) y Sor Arcangela Tarabotti, Las mujeres son de la misma especie que los hombres (edición y traducción de Mercedes Arriaga, Diana de Paco, Juan Aguilar, Daniele Cerrato, Sevilla, Arcibel, 2013). ocurre cuando las tildan de tener una mente débil, carente de razón, a la vez que, contradictoriamente, las tachan de ser demasiado astutas:

Y con todo esto, apelando yo no sólo al sentimiento común, sino también a la experiencia común, debo aquí recordar que a las Mujeres se les suele atribuir un entendimiento sutil. ¿Y no es éste el sexo que es acusado de fraudulento y de demasiado astuto? (Califronia, 2013: 89).

Por otra parte, Califronia impreca a los varones ilustrados, reprobando las nefastas demostraciones que han dado de sí mismos y de sus cuestionables virtudes. Como prueba de ello, les recuerda el ingente número de hombres que pueblan las cárceles y los reformatorios, que contrasta sobremanera con los innumerables méritos y proezas demostrados por las mujeres:

En el siglo XVI, se ha escrito mucho en honor de las Mujeres; un poco también en el siguiente siglo XVII, poquísimo en este siglo, que se denomina iluminado. ¿Acaso se han iluminado los hombres sobre los vicios de las Mujeres, cuando, en este mismo siglo, hemos visto los más horrendos vicios de los propios hombres, y gloriosísimas proezas del sexo femenino? (Califronia, 2013: 65).

¿De qué género son comúnmente los ladrones y los asesinos? ¿Son del femenino o del masculino? ¿Cuándo se ha oído que las Mujeres sean las asesinas de los viajeros? ¿Las cárceles públicas de qué están llenas? ¿De Mujeres o de hombres? ¿Las horcas y las hachas para qué especie se emplean? ¿Para la femenina o para la de los varones? ¿Las galeras de qué abundan? ¿Los presidios? Si hay correccionales, ¿de qué abundan más? Y en éstos hay también una diferencia bastante remarcable. En los reformatorios y en los correccionales apenas hay alguna jovencita, mientras que están llenos de jóvenes y jovenzuelos, que, en tierna edad, 
demuestran estar ya perfeccionados en los vicios (Califronia, 2013: 109).

Dicha constatación choca con las extremas limitaciones educativas impuestas a las mujeres, que, no obstante, no han supuesto un obstáculo para que, en su mayoría, hayan sabido comportarse con rectitud y dignidad en el transcurso de la historia. Por ello, tal y como sostiene la escritora, si se les concediera una formación adecuada, tendrían ocasión de destacar aún más; demostrando que pueden ser, incluso, superiores a los hombres.

Al mismo tiempo, definiéndose a sí misma como moderadora y juez imparcial, si bien defiende las innumerables virtudes de las de su sexo, no dudará en reprobar también sus defectos; reconociendo algunas de las acusaciones que se les imputan:

Hay que añadir también que yo me preparo no contra todas las acusaciones hechas a mi sexo, sino solamente contra las calumnias. Soy yo la primera en confesar que hay muchas acusaciones contra nosotras que son verídicas. Las Mujeres honestas no buscan defensa, sino que buscan arrepentimiento, y reforma, para las semejantes que tengan necesidad de ello (Califronia, 2013: 69, 71).

Pero tienen algunos vicios las Mujeres. ¿Quién lo ha negado? [...] No soy yo aquí la abogada ecuménica de mi noble sexo. Yo sólo debía demostrar el menor número de los vicios y defectos de las Mujeres con respecto a los hombres; y creo haber hecho brevemente una demostración suficiente (Califronia, 2013: 173).

Por ello, las anima a seguir obrando con la misma rectitud, sensatez y agudo ingenio que han mostrado a lo largo de la historia, con humildad y sin apartarse de sus deberes y responsabilidades, pues solo así evitarán adquirir los mismos vicios y defectos que aquellos engreídos varones que, con extrema ignorancia, se jactan de poseer el don del conocimiento supremo:

Las Mujeres, por tanto, que no confundan el ingenio con la ciencia, que no razonen más que de aquellas materias de las que tienen suficiente conocimiento, y mantengan un prudente y escrupuloso silencio en todas las demás, de las que no pueden haberse adquirido los conocimientos. Dije escrupuloso silencio porque hay que examinar cada una con diligencia, para que no se crea fácilmente poseer el conocimiento de aquellas materias de las que aún uno no está en legítima posesión (Califronia, 2013: 69).

No sin cierta ironía en sus argumentaciones y dirigiéndose a los hombres, Califronia, con su tratado, asegura estar obrando también en beneficio de estos, al librarlos de tan negativos pensamientos contra las mujeres. Por otra parte, asumiendo un tono conservador y maternal, las invita a ellas a no envanecerse ni a mostrarse arrogantes al verse arropadas por su elocuente y justa defensa, recomendándoles que conserven siempre su prudencia y sensatez:

Defendiendo yo a las Mujeres de las acusaciones contra ellas, les quitaré a los hombres aquel disgusto que sienten en su necesaria vida común con las hembras; disgusto nacido en la mente de los varones por una errónea opinión sobre los no existentes defectos de mi sexo; por lo que yo también les proporcionaré, con mi arenga, un verdadero provecho. Tampoco, por esto, será dada ocasión legítima a las Mujeres de ensoberbecerse o de vengarse de sus injustos acusadores. Cualquier bien que tiene el hombre mortal no se lo trajo consigo en su venida al mundo, pues nada suyo tenía antes de entrar en él. Por tanto, toda la gloria es del Hacedor de todo bien. De esto, pues, no es dueño el hombre, sino que es un depositario, que tendrá que rendir exactísimas cuentas al supremo autor (Califronia, 2013: 69). 
Además del recurso a la ironía, muy frecuente en los textos de las escritoras que, durante siglos, participaron en el debate de la querella de las mujeres, Califronia también recurrirá a otras estrategias estilísticas para que su discurso resultara más atractivo y convincente. De este modo, con un estilo elegante, pero, a la vez, sencillo, para que sus ideas pudieran penetrar sin dificultad en un amplio público, se valdrá, con frecuencia, de las metáforas y los símiles para expresar su pensamiento. Recursos, por otra parte, también muy habituales en las Sagradas Escrituras y otros textos religiosos y filosóficos de los que, sin duda, como ya hemos mencionado, la escritora se ha embebido. Así, por citar un ejemplo representativo, en el siguiente fragmento, la autora identifica a las mujeres con "los más altos árboles" y al pensamiento misógino con una "hoz afilada" que pretende derribarlos:

Hecho, pues, el justo análisis, han sido menospreciadas, en sustancia, las Mujeres, mientras se proclamaban, a voces y por todas partes, los privilegios y los derechos del hombre; y mientras se ha querido segar, con una hoz afilada, los más altos árboles para reducir todos los productos del campo a perfecta igualdad (Califronia, 2013: 63).

Cabe, por último, señalar que si bien, en muchas ocasiones, la supuesta condesa se muestra comedida en sus pretensiones e, incluso, en ciertos razonamientos, condescendiente con los hombres; en otras, no repara en emitir duros juicios contra los difamadores del sexo "débil", arremetiendo contra ellos con calificativos como: "varones eruditillos", "resabidos logiquillos", "logicuchos aristotélicos", "miserables sabihondillos", "capones gordos y delgados", "filosofillos", "necios", "atontados"...; lo cual demuestra que la causa que está defendiendo le afecta direc- tamente, encendiendo todas sus furias. Sin embargo, también pudiera tratarse de una estrategia para reprobarlos libremente, en el supuesto de que el tratado estuviera escrito por un varón, desviando su atención hacia una hipotética autora, al recurrir al uso de numerosos diminutivos y apelativos más propios del lenguaje femenino (González, 2017: 38-39).

Independientemente de su autoría y no obstante su tono más moderado y menos reaccionario que el que podría esperarse en una época tan revolucionaria y decisiva para la historia del feminismo, es innegable el valor de la Breve difesa dei diritti delle Donne, pues supuso un paso adelante, un grano más de arena, en las reivindicaciones precursoras del feminismo que, cada vez con mayor intensidad y tesón, a distancia de apenas dos siglos, conseguirán los grandes logros de los que tantas mujeres gozamos hoy en día.

\section{Bibliografía}

Arouet, F. M., (Voltaire), Diccionario filosófico, edición de A. Martínez Arancón, tomo II, Ediciones Temas de Hoy, Madrid, 1764.

Arriaga Flórez, M., "Teorías feministas ante literam: las mujeres que escriben tratados en los siglos XV y XVI en Italia", Feminismo y literatura, "La Página", n. 29, 1997, pp. 43-50.

Betri M. L., Brambilla, E., Salotti e ruolo femminile in Italia. Tra fine Seicento e primo Novecento, Marsilio, Venecia, 2004.

Califronia, R., Breve defensa de los derechos de las Mujeres (Breve difesa dei diritti delle Donne), edición crítica y traducción de Mercedes González de Sande (versión bilingüe italiano-español), Arcibel, Sevilla, 2013. 
Cervini, L., "Tras la máscara de Rosa Califronia, condesa romana", en AA.VV, Máscaras femeninas. Ficción, simulación y espectáculo, Arcibel, Sevilla, 2010, pp. 329-340.

Condorcet, N. (de), Bosquejo de un cuadro histórico de los progresos del espíritu humano, ed. de A. Torres del Moral y M. Suárez, Editora Nacional, Madrid, 1980 [1793].

De Gouges, O., Declaración de los derechos de la mujer y de la ciudadana, 1791; texto consultable en "DHpedia. La Enciclopedia libre de los derechos humanos", https://dhpedia.wikis.cc/wiki/Declaraci\%C3\%B3n_de_los_Derechos_de_la_ Mujer_y_de_la_Ciudadana

De Leo, M., Taricone, F., Le donne in Italia. Diritti civili e politici, Liguori, Nápoles, 1992.

De Martino, G., Bruzzese, M., Le Filosofe. Le donne protagoniste nella storia del pensiero, Liguori Editori, Nápoles, 1994.

Diderot, D., Condillac, É. B., d'Alembert, J. L., Encyclopédie, ou Dictionnaire Raisonné des Sciences, des Arts et des Métiers, Vol. 3, Antoine-Claude Briasson, MichelAntoine David, Laurent Durand, París, 1753, consultable en: http://enccre.academie-sciences.fr/encyclopedie/. Consulta 10/06/2021.

González de Sande, M., "El florecimiento cultural de las mujeres en el siglo XVIII italiano", RSEI. Revista de la Sociedad Española de Italianistas, 11, 2015-2017, pp. 165-175.

González de Sande, M., "La Breve difesa dei diritti delle Donne y algunas cuestiones sobre su autoría", en A. Guzmán e I. Velázquez (eds.), De Falsa et Vera Historia I. Estudios sobre falsificación documental y literaria antigua, Ediciones Clásicas, Madrid, 2017, pp. 27-40.

González de Sande, M., "Las mujeres en la Italia del siglo XVIII: el largo camino hacia la conquista de sus derechos", en M. Bianchi y M. Martín Clavijo (eds.), Desafiando al olvido: escritoras italianas inéditas, Ediciones de la Universidad de Salamanca, Salamanca, 2018, pp. 101-114.

Guerci, L., La discussione sulla donna nell'Italia del Settecento. Aspetti e problemi, Tirrenia, Turín, 1987.

Matthews-Grieco, S. F., Monaca, moglie, serva, cortigiana: vita e immagine delle donne tra Rinascimento e Controriforma, Morgana, Florencia, 2001.

Messbarger, R., The century of women, Representations of women in eighteenth century Italian public discourse, University of Toronto Press, Toronto, 2002.

Messbarger, R., Findlen, P., The Contest for Knowledge: Debates over Women's Learning in Eighteenth-Century Italy, University of Chicago Press, Chicago, 2005.

Montanelli, I., Gervaso, R., L'Italia del Settecento (1700-1789), Rizzoli, Milán, 1973.

Natali, G., "Gli studi delle donne", in /I Settecento, vol. I, Vallardi, Milán,1964, pp. 120-157.

Puleo, A. H., La Ilustración olvidada. La polémica de los sexos en el siglo XVIII, Anthropos, Madrid, 1993.

Rousseau, J. J., Emilio, o De la educación, Alianza Editorial, Madrid, 1998 [1762].

Wollstonecraft, M., Vindicación de los derechos de la Mujer, 1791, consultable en la web: https://freeditorial.com/es/books/ vindicacion-de-los-derechos-de-la-mujer. Consulta 10/06/2021. 